\title{
Tuning complement activation and pathway through controlled molecular architecture of dextran chains in nanoparticle corona
}

\author{
Jean-Baptiste Coty $^{\mathrm{a}}$, Elquio Eleamen Oliveira ${ }^{\mathrm{a}, \mathrm{b}}$, Christine Vauthier ${ }^{\mathrm{a} *}$ \\ ${ }^{a}$ Institut Galien Paris-Sud, CNRS, Univ. Paris-Sud, Châtenay-Malabry, France. \\ ${ }^{\text {b } C e n t r o ~ d e ~ C i e ̂ n c i a s ~ B i o l o ́ g i c a s ~ e ~ S o c i a i s ~ A p l i c a d a s, ~ U n i v e r s i d a d e ~ E s t a d u a l ~ d a ~ P a r a i ́ b a, ~ J o a ̃ o ~ P e s s o a, ~ P B ~}$ \\ 58070450, Brazil
}

Published in: Int J Pharm. 2017;532(2):769-778. doi: 10.1016/j.jjpharm.2017.04.048.
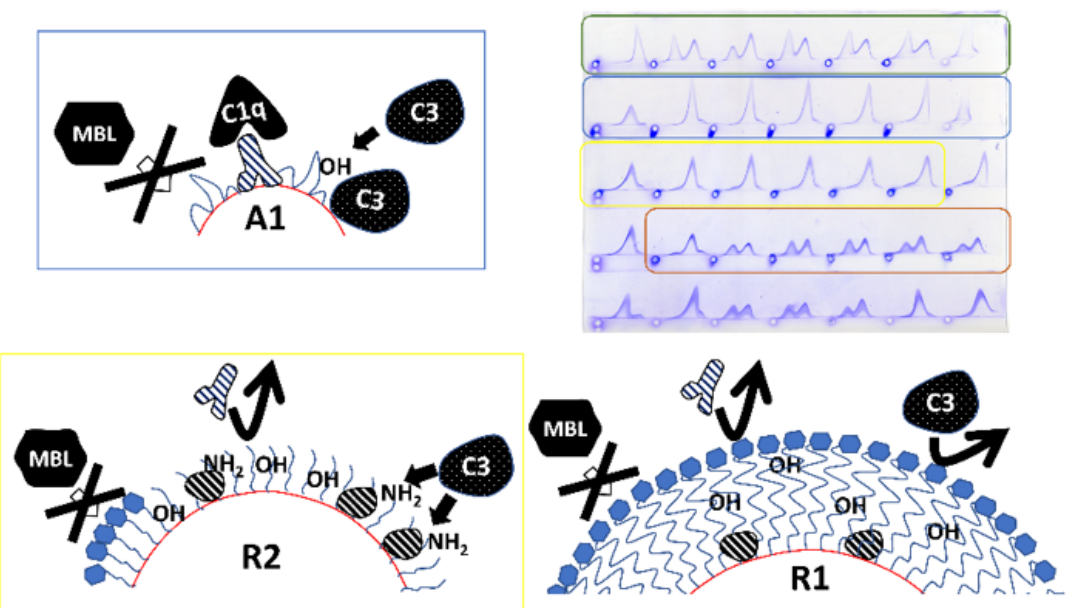
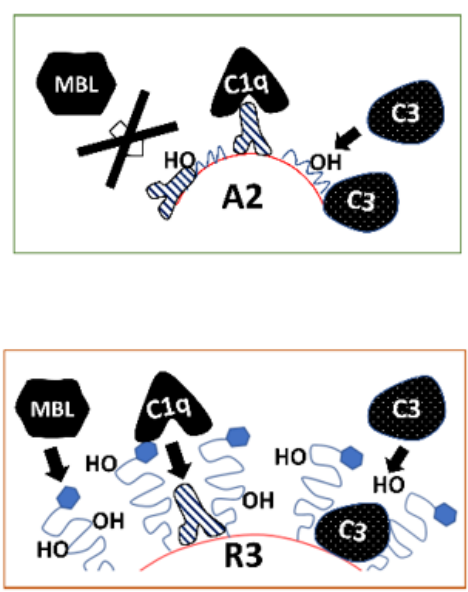

\begin{abstract}
The understanding of complement activation by nanomaterials is a key to a rational design of safe and efficient nanomedicines. This work proposed a systematic study investigating how molecular design of nanoparticle coronas made of dextran impacts on mechanisms that trigger complement activation. The nanoparticles used for this work consisted of dextran-coated poly(isobutylcyanoacrylate) (PIBCA) nanoparticles have already been thoroughly characterized. Their different capacity to trigger complement activation established on the cleavage of the protein C 3 was alsoalready described making these nanoparticles good models to investigate the relation between the molecular feature of their corona and the mechanism by which they triggered complement activation. Results of this new study shows that complement activation pathways can be selected by distinct architectures formed by dextran chains composing the nanoparticle corona. Assumptions that explain the relation between complement activation mechanisms triggered by the nanoparticles and the nanoparticle corona molecular feature were proposed. These results are of interest to better understand how the design of dextran-coated nanomaterials will impact on interactions with the complement system. It can open perspectives with regard to the selection of a preferential complement activation pathway or prevent the nanoparticles to activate the complement system, based on a rational choice of the corona configuration.
\end{abstract}

Key words Nanoparticles, complement activation pathway, corona, molecular feature, molecular architecture

*Corresponding Author: Christine Vauthier. Institut Galien Paris-Sud, CNRS UMR 8612, Univ. ParisSud, Faculté de Pharmacie, 5 Rue J.B. Clément, 92296 Châtenay-Malabry, France.

E-mail : christine.vauthier@u-psud.fr, Fax : +33 146835946 / Phone : + 33146835603 


\section{Introduction}

Nanoparticles have been extensively studied as drug delivery systems for therapeutic purposes (Couvreur and Vauthier 2006, Crucho and Barros, 2015, Li et al., 2015, Shi et al., 2017). Success to improve therapeutic index of molecules carried by such systems depends on the fate of the nanoparticles in the body. The rational design of new carriers is pending to a better understanding of the relationship between nanoparticles' properties and their interactions with the biological medium surrounding the nanoparticles once they are in the body (Clogston et al., 2016, Ilinskaya and Dobrovolskaia, 2016a, 2016b, Orfi and Szebeni, 2016, Szeto and Lavik, 2016, Truel and Nienboss, 2013, Xiang et al., 2013). In general, nanoparticles are designed to be administered intravenously. Once in the blood, they are immediately confronted with components of the innate immune system (Anchordoquy et al., 2017, Dobrovolskaia and McNeil, 2013, Moghimi and Farhangrazi, 2013, Szebeni, 2014). Without specific engineering, nanoparticles are generally recognized by the innate immune system and rapidly cleared from the bloodstream due to the uptake by the mononuclear phagocyte system (MPS) (Bazile et al., 1995, D’Addio et al., 2012, Gref et al., 1995, 1994, Peracchia et al. 1999, Suk et al. 2016). Several works have demonstrated that the grafting of a hydrophilic corona at the surface of the nanoparticles can reduce the uptake by MPS. Hydrophilic polymers, such as polyethylene glycol (PEG), polysaccharides (e.g. dextran, heparin, and chitosan) and polyphosphoesters were the most used materials on this purpose (Alhareth et al., 2012, Bazile et al., 1995, Bertholon et al., 2006a, D'Addio et al., 2012, Gref et al., 1995, 1994, Moghimi and Szebeni, 2003, Muller et al., 2017, Lemarchand et al., 2006, Peracchia et al., 1999, Suk et al., 2016). However, a review of the literature shows that even with a hydrophilic corona, some nanocarriers undergo a rapid clearance that is accompanied by the activation of the complement system (Alhareth et al., 2012, Gref et al., 2000, Moghimi et al., 2003, Szebeni, 2014). The effectiveness of the hydrophilic shell to reduce uptake by MPS is associated with its capability to reduce interactions of blood proteins with the nanoparticle surface. All parameters that define the molecular feature of the hydrophilic corona formed around the nanoparticles, i.e. chain length, grafting density, composition and structural arrangement of the chains, were found important factors influencing the in vivo fate of nanoparticles (Chen and Borden, 2011, D'Addio et al., 2012, Du et al., 2015, Hamad et al., 2010, Muller et al., 2017, Peracchia et al., 1997, Toda et al., 2010, Szebeni et al., 2015, Szeto and Lavik, 2016, Vonarbourg et al., 2006).

The complement system (CS) has an important role in innate immunity to recognize and eliminate pathogens, defective cells and foreign biomaterial devices, including nanoparticles circulating in the blood (Carroll and Sim, 2011). The CS consists of more than 30 plasma and cell-membrane proteins. It is the most important biochemical cascade that defines the type of "danger" signals sent to the rest of the immune system after it has detected an intruder, hence defining the type of response. Its activation can be triggered essentially by three distinct routes, the classical, lectin and alternative pathways (Gasque, 2004, Harboe et al., 2011, Merle et al., 2015). The classical pathway is activated primordially by the interaction of $\mathrm{C} 1 \mathrm{q}$ with immunoglobulins. Non-immune molecules such as the $\mathrm{C}$ reactive protein (CRP) can also trigger the classical pathway. The lectin pathway is triggered by the recognition of carbohydrate patterns exhibited on the surface of foreign particles. Proteins involved in the recognition are the mannose-binding lectin (MBL), the $\mathrm{H}-, \mathrm{L}-$ or $\mathrm{M}$-ficolins or the collectin 11 . Activation of the alternative pathway depends on spontaneous hydrolysis of the internal thioester bond found in protein $\mathrm{C} 3$ that can be triggered by nucleophilic groups found on the intruder surfaces. 
The three pathways converge to generate the C3 convertase and the terminal membrane attack complex (MAC) C5b-9. Activation of the CS also leads to the release of many types of anaphylatoxins which contribute to the inflammatory process (Carrol and Sim, 2011)

Interactions of proteins of the CS with colloidal particles can trigger the complement cascade (Bertholon et al., 2006a, Dobrovolskaia and McNeil, 2013, Ilinskaya and Dobrovolskaia, 2016a, 2016b, Lorenze-Abalde et al. 2016, Moghimi and Farhangrazi, 2013, Szebeni, 2014, Szebeni et al., 2012, VorupJensen and Boesen, 2011). Then, the production of opsonins such as C3b lead to a rapid capture of nanocarriers by the MPS resulting in a short circulation time in the blood. While this effect can compromise the efficacy of delivery systems, another consequence of the activation of the complement system concerns its safety when it gives rise to hypersensitivity reactions called complement activation-related pseudoallergy (CARPA) (Andersen et al., 2012, Szebeni, 2014, 2012, Szebeni et al., 2012).

Nanoparticles based on biodegradable poly(alkylcyanoacrylate) polymers were widely investigated as drug delivery systems (Couvreur and Vauthier, 2006, Nicolas and Couvreur, 2009, Nicolas et al., 2013, Nicolas and Vauthier, 2011, Vauthier et al., 2007). These colloidal carriers have shown many advantages in terms of drug protection, long stability, biocompatibility, biodegradability and drug delivery potential. Different preparation methods can be used to generate poly(isobutylcyanoacrylate) PIBCA nanoparticles having hydrophilic coronas of various compositions and molecular architectures modulating their capacity to activate the complement system and their biodistribution (Vauthier, 2015). A series of PIBCA nanoparticles with different hydrophilic coronas made of dextran was thoroughly characterized in previous works (Bertholon et al., 2006b, 2006c, Chauvierre et al., 2004, Labarre et al., 2005, Vauthier et al., 2011, 2009). These nanoparticles could serve as models to improve our understanding of the influence of the molecular feature of the hydrophilic polymers of the nanoparticle corona on biological mechanisms involved in efficacy and safety of nanoparticles. Such a work would be consistent with the need to develop systematic studies providing results required to improve our capacity to design efficient and safe nanoparticulate drug delivery systems on more rational basis (Clogston et al., 2016, Szeto and Lavik, 2016, Truel and Nienhaus, 2013, Xiang et al., 2013).

The goal of the present work was to evaluate how molecular characteristics of the corona of dextrancoated PIBCA nanoparticles could interfere in the activation of the complement system, including the resolution of the involved pathway(s). Activation of the complement cascade was acknowledged in a systematic way by evidencing protein C3 cleavage using a high-throughput serial 2D immunoelectrophoresis method (Coty et al., 2016). Pathways were differentiated incubating nanoparticles and serum with calcium and magnesium to highlight complement activation triggered through all pathways and with magnesium only to evidence the contribution to activation of the alternative pathway that is a calcium independent pathway (Des Prez et al., 1975, Hamad et al., 2010, Labarre et al., 1993). Results were discussed in the light of our knowledge on the molecular characteristics of the nanoparticle corona. 


\section{Materials and Methods}

\subsection{Materials}

Isobutylcyanoacrylate (IBCA) was synthesized and provided by Orapi (Saint-Vulbas, France). Chemicals purchased from Sigma (Saint-Quentin-Fallavier, France) were tricine, Tris base (Sigma 7-9 ${ }^{\circ}$ ), sodium chloride, EDTA sodium salt, dextran 66.7 kDa, and bromophenol blue. Dextran 17.7, cerium (IV) ammonium nitrate, nitric acid, and chloride acid were supplied by Fluka (Saint-Quentin-Fallavier, France). Nitric acid was purchased from Prolabo (Paris, France). Calcium lactate, glacial acetic acid, coomassie brilliant blue R-250 were supplied by Thermo Fisher Scientific (Villebon-sur-Yvette, France). Gel-Fix ${ }^{\text {TM }}$ for agarose $(265 \times 150 \mathrm{~mm})$ was obtained from Serva Electrophoresis (Heidelberg, Germany). Nafamostat mesylate (NM) was obtained from Abcam (Cambridge, UK). All chemicals were of reagent grade and used as purchased.

Polyclonal anti-human C3 antibody raised in goat was purchased from Fitzgerald antibodies (Acton, USA). Serum was prepared from human plasma obtained from healthy donors from Etablissement Français du Sang (EFS) (Rungis, France). Heat-activated gamma globulin (HAGG) and Cobra Venom Factor (CVF) were purchased from TECO Medical (Rambouillet, France) to be used as positive control for the activation of the complement system.

\subsection{Preparation of nanoparticles by redox radical emulsion polymerization (RREP)}

Three types of RREP nanoparticles were prepared according to the method described by Bertholon et al. (2006c). R1 and R2 were prepared as follow using dextran 66.7 kDa and dextran $17.7 \mathrm{kDa}$ respectively at a concentration of $1.3 \%$. Dextran $(0.1356 \mathrm{~g})$ was dissolved in $8 \mathrm{~mL}$ of $0.2 \mathrm{~N}$ nitric acid. After 10 min bubbling with argon at $40^{\circ} \mathrm{C}$, the polymerization was initiated adding successively and under vigorous stirring $2 \mathrm{~mL}$ of a solution of cerium (IV) ammonium nitrate $\left(8 \times 10^{-2} \mathrm{M}\right)$ in $0.2 \mathrm{~N}$ nitric acid and $0.5 \mathrm{~mL}$ of IBCA. The reaction was allowed to continue for $1 \mathrm{~h}$ at $40^{\circ} \mathrm{C}$. At the end, the dispersion was cooled down in an ice bath.

R3 was prepared following the same method using a concentration of dextran $66.7 \mathrm{kDa}$ of $0.5 \%$. Dextran $66.7 \mathrm{kDa}(0.0502 \mathrm{~g})$ was dissolved in $9.3 \mathrm{~mL}$ of $0.2 \mathrm{~N}$ nitric acid following the above described protocol. The polymerization was started by adding successively $0.7 \mathrm{~mL}$ of a solution of cerium (IV) ammonium nitrate $\left(8 \times 10^{-2} \mathrm{M}\right)$ in $0.2 \mathrm{~N}$ nitric acid and $0.5 \mathrm{~mL}$ of IBCA. At the end of the polymerization the dispersion was cooled down at $4^{\circ} \mathrm{C}$.

\subsection{Preparation of nanoparticles by anionic emulsion polymerization (AEP)}

Nanoparticles A1 were prepared according to the method described in Bertholon et al. (2006c). Dextran $66.7 \mathrm{kDa}(0.1375 \mathrm{~g})$ was dissolved in $10 \mathrm{~mL}$ of $0.2 \mathrm{~N}$ nitric acid $(\mathrm{pH} 1)$. IBCA $(0.5 \mathrm{~mL})$ was added to the solution and stirred for $24 \mathrm{~h}$ at $40^{\circ} \mathrm{C}$. At the end of the polymerization, the dispersion was cooled down in an ice bath.

Nanoparticles A2 were prepared according to the method of Couvreur et al. (1979) Dextran $66.7 \mathrm{kDa}$ $(0.05 \mathrm{~g})$ was dissolved in $10 \mathrm{~mL}$ of a solution of $3 \mathrm{mM} \mathrm{HCl}(\mathrm{pH} 2.5)$. Then, $100 \mu \mathrm{L}$ of IBCA was added while the system was placed under vigorously stirring. The polymerization was lasted for $3 \mathrm{~h}$ at room temperature. 


\subsection{Purification of nanoparticles}

All nanoparticle dispersions were purified by dialysis against water after polymerization Spectra/Por membrane with molecular weight cutoff $100 \mathrm{KDa}$ ). After purification, they were stored at $4^{\circ} \mathrm{C}$ until use.

\subsection{Evaluation of nanoparticle concentrations in dispersions}

To estimate nanoparticles' concentration in dispersions, aliquots of $100 \mu \mathrm{L}$ each were freeze-dried and weighed. The determination was done in triplicated. Results were given as the mean of the three determinations in $\mathrm{mg}^{\mathrm{mL}} \mathrm{m}^{-1}$. This concentration was converted into a concentration expressed in surface area per volume unit to be used in tests designed to evaluate complement activation triggered by the nanoparticles. The conversion was obtained using the equation given in Vittaz et al. (1996) taking the hydrodynamic diameter of the nanoparticles measured by dynamic light scattering (see paragraph 2.6) and the volume mass of the nanoparticles at 1.14 (Vauthier et al. 1999).

\subsection{Measurement of particle size and zeta potential}

The mean hydrodynamic diameter of the nanoparticles was evaluated by dynamic light scattering using a Zetasizer Nano ZS90 (Malvern Instruments, Orsay, France) operating at $90^{\circ}$. The samples $(5-20 \mu \mathrm{L})$ were diluted in MilliQ ${ }^{\circ}$ water $(1 \mathrm{~mL})$.

The zeta potential of the nanoparticles was evaluated from the measurements of the electrophoretic mobility of the nanoparticles using a Zetasizer Nano ZS90 (Malvern Instruments, Orsay, France). Dilutions of the samples were performed in an aqueous solution of $1 \mathrm{mM} \mathrm{NaCl}$.

\subsection{Evaluation of complement activation by two-dimensional immunoelectrophoresis of C3}

Complement activation triggered by the nanoparticles was assessed by evaluating conversion of $\mathrm{C} 3$ into activated fragments of lower molar mass by serial multiple crossed immunoelectrophoresis at a microscale using polyclonal antibody to human C3 (Coty et al. 2016). Pathway by which complement activation was triggered was identified incubating nanoparticles and serum with buffers containing different concentrations in calcium and magnesium in order to highlight the part of the activation due to calcium dependent/independent mechanisms (Banda et al., 2014, Des Pres et al., 1975, Hamad et al., 2010, 2008, Labarre et al., 1993).

Veronal buffered saline named $\mathrm{VBS}^{2+}$ containing $5 \mathrm{mM}$ diethylmalonylurea, $0.15 \mathrm{mM}$ calcium chloride, $0.5 \mathrm{mM}$ magnesium chloride, $150 \mathrm{mM}$ sodium chloride, $\mathrm{pH} 7.4$ was used to investigate complement activation triggered by all pathways. Veronal buffer saline named $\mathrm{VBSMg}^{2+} \mathrm{X} / \mathrm{EGTA}$ containing $5 \mathrm{mM}$ diethylmalonylurea, 0.5 to $10(\mathrm{X}) \mathrm{mM}$ magnesium chloride, $150 \mathrm{mM}$ sodium chloride, $10 \mathrm{mM}$ EGTA pH 7.4 were used for incubations of the nanoparticles with human serum to investigate complement activation triggered by calcium independent pathways including the alternative pathway. It is noteworthy that the composition of $\mathrm{VBS}^{2+}$ and of VBSMg0.5mM/EGTA corresponded to those generally found in the literature and in commercial assays to assess in vitro evaluation of complement activation (Des Prez et al., 1975, Hamad et al., 2010, Labarre et al., 1993, Neun et al., 2015).

Nanoparticle dispersions $(50 \mu \mathrm{L})$ were incubated under gentle agitation for $1 \mathrm{~h}$ at $37^{\circ} \mathrm{C}$ with $25 \mu \mathrm{L}$ human serum and $25 \mu \mathrm{LVBS}^{2+}$ or VBSMg ${ }^{2+}$ X/EGTA to evaluate the activation of the complement system 
triggered by the nanoparticles produced in the different conditions of incubations. Concentrations in nanoparticles involved in the test were expressed as the surface area per volume unit $\left(\mathrm{cm}^{2} \cdot \mathrm{mL}^{-1}\right)$ to ensure a relevant comparison between the different nanoparticles that were characterized by different sizes.

In one series of experiments, nanoparticles were tested using $\mathrm{VBS}^{2+}$ at a concentration in nanoparticles of $2000 \mathrm{~cm}^{2} \cdot \mathrm{mL}^{-1}$. A second series of experiments were performed using $V B S M g^{2+} X / E G T A$ at concentrations in magnesium $(X)$ ranging from 0.5 to $10 \mathrm{mM}$ at the same concentration in nanoparticles $\left(2000 \mathrm{~cm}^{2} \cdot \mathrm{mL}^{-1}\right)$. In a second series of experiments, the nanoparticles were tested for their capacity to activate $\mathrm{CS}$ in VBS ${ }^{2+}$ at a higher concentration $\left(4000 \mathrm{~cm}^{2} \cdot \mathrm{mL}^{-1}\right.$ for nanoparticles R1, R2 and $A 1,2500$ and $2800 \mathrm{~cm}^{2}$. $\mathrm{mL}^{-1}$ for nanoparticles $\mathrm{A} 2$ and $\mathrm{R} 3$ respectively). Nanoparticles activating CS in these conditions were then tested in calcium free media using $\mathrm{VBSMg}^{2+} \mathrm{X} / \mathrm{EGTA}$ buffers at concentrations in magnesium $(X)$ ranging from 0.5 to $10 \mathrm{mM}$. A series of control experiments were added as follow. A sample of serum in which the nanoparticles were replaced by Milli- $Q^{\circ}$ water was tested to evaluate the rate of spontaneous activation of CS triggered in all different conditions of incubations used in this study. Cobra venom factor (CVF) and heat agglomerated gamma-globulins (HAGG) were used as positive control of the activation of CS. With CVF, activation of CS was expected to occur in all the tested conditions because CVF is a strong complement activator through the alternative pathway. CVF structure being very similar to C3b, it allows the spontaneous formation of C3 and C5 convertases spontaneously (Vogel ad Fritzinger, 2010). In contrast, with the heat-aggregated gamma globulins (HAGG), activation that is expected to occur through the classical pathway should not induce the cleavage of the protein $\mathrm{C} 3$ while incubations were performed in the absence of calcium ions $\left(\mathrm{VBSMg}^{2+} \mathrm{X} / \mathrm{EGTA}\right)$. These positive control samples were selected consistently with those used in protocol evaluating the activation of the complement system proposed by the Nanomedicine Characterization Laboratory in the USA (Neun et al., 2015)

After incubation, the cleavage of the C3 protein was evaluated analyzing $2.5 \mu \mathrm{L}$ of the incubation medium by $2 \mathrm{D}$ immunoelectrophoresis performed in agarose gels containing a polyclonal anti-human C3 antibody that recognizes both native and activated C3. The 2D immuoelectrophoresis was performed as described in Coty et al. (2016). Briefly, an agarose gel (1\% in agarose) containing the antibody was casted on a gel bond slab $(15 \times 20 \mathrm{~cm})$ at $60^{\circ} \mathrm{C} .5$ bands of $1 \mathrm{~cm}$ each were cut and removed to be replaced by neutral agarose gel at $1 \%$. Seven wells were formed in lines in the bands of neutral agarose gel where $2.5 \mu \mathrm{L}$ of samples were deposited for analysis. The gel slab was charged with 35 samples and the first dimension of the electrophoresis $(16 \mathrm{~mA}, 600 \mathrm{~V}, 100 \mathrm{~W})$ was run in the presence of bromophenol blue as migration marker. When the migration marker has run for $6 \mathrm{~cm}$ from the well (approximatively $1 \mathrm{~h} 15 \mathrm{~min}$ ), the electrophoresis was stopped, the gel slab was turned from $90^{\circ}$ and the second electrophoresis was started $(12 \mathrm{~mA}, 500 \mathrm{~V}, 100 \mathrm{~W})$ for $3 \mathrm{~h} 30 \mathrm{~min}$. At the end of the electrophoresis, the gel slab was dried using papers and then stained with coomassie blue. The obtained gel slab was scanned at a high resolution and the electrophoregrams were analyzed to evaluate the area of the peak corresponding to the native C3 protein and that of the activated fragments using image J. The final results were expressed as the percentage of the area of the peaks corresponding to the activated fragments (ACAF) per the sum of the areas measured for peaks corresponding to the native (AC3) and activated fragments (ACAF)

$R=A C A F /(A C 3+A C A F)$ 
All determinations were made in triplicates.

\section{Results}

\subsection{Nanoparticles Characteristics}

Characteristics of nanoparticle dispersions are given in table 1. Results agreed well with those found in previous studies emphasizing the reproducibility of the preparation of this series of nanoparticles regarding their principal physicochemical characteristics $(15,36)$ (Alhareth et al., 2012, Bertholon et al., 2006a, 2006b, Vauthier et al., 2011, 2009).

Table 1: Hydrodynamic diameter, polydispersity index and zeta potential of the nanoparticles prepared by the different methods and used in the current work.

\begin{tabular}{|l|l|l|l|l|l|}
\hline № & $\begin{array}{l}\text { Polymerization } \\
\text { method }\end{array}$ & $\begin{array}{l}\text { Dextran } \\
\text { Mw, percentage added in } \\
\text { the polymerization } \\
\text { medium }\end{array}$ & $\mathrm{d}_{\mathrm{H}}(\mathrm{nm})$ & PDI & $\begin{array}{l}\text { Zeta Potential } \\
(\mathrm{mV})\end{array}$ \\
\hline R1 & RREP at pH 1 & $66.7 \mathrm{kDa}, 1.3 \%$ & $291 \pm 0.6$ & 0.069 & -4.45 \\
\hline R2 & RREP at $\mathrm{pH} 1$ & $17.7 \mathrm{kDa}, 1.3 \%$ & $234 \pm 1.7$ & 0.077 & -12.6 \\
\hline R3 & RREP at $\mathrm{pH} 1$ & $66.7 \mathrm{kDa}, 0.5 \%$ & $291 \pm 1.0$ & 0.040 & -5.31 \\
\hline A1 & AEP at $\mathrm{pH} 1-$ & $66.7 \mathrm{kDa}, 1.3 \%$ & $85 \pm 0.7$ & 0.056 & -4.33 \\
\hline A2 & AEP at $\mathrm{pH} 2.5$ & $66.7 \mathrm{kDa}, 0.5 \%$ & $113 \pm 1.1$ & 0.147 & -6.37 \\
\hline
\end{tabular}

RREP: redox radical emulsion polymerization, AEP: anionic emulsion polymerization, Mw: Molecular Weight.

\subsection{In vitro complement activation}

Activation of the complement system was investigated highlighting the cleavage of the protein C3 after incubation of nanoparticles with serum using a recently developed high-throughput 2D immunoelectrophoresis method (Coty et al. 2016). The protein C3 is the first protein of the complement cascade that is activated regardless of the activation pathway triggered. Activation of the complement system requires divalent cations including magnesium and calcium. The classical and lectin pathways need calcium and magnesium being calcium dependent while the alternative pathway that is calcium independent only requires magnesium. Based in these specificities, it is possible to investigate pathways by which nanotechnologies trigger the complement system by varying the concentration in calcium in testing conditions (Banda et al., 2014, Des Pres et al., 1975, Hamad et al., 2010, Labarre et al., 1993). 
Figures 1, 2 and 3 show the cleavage of the protein C3 observed after incubation of serum with nanoparticles in the different conditions. Figure 1 demonstrated the relevancy of the test reporting the analysis performed with different control samples.

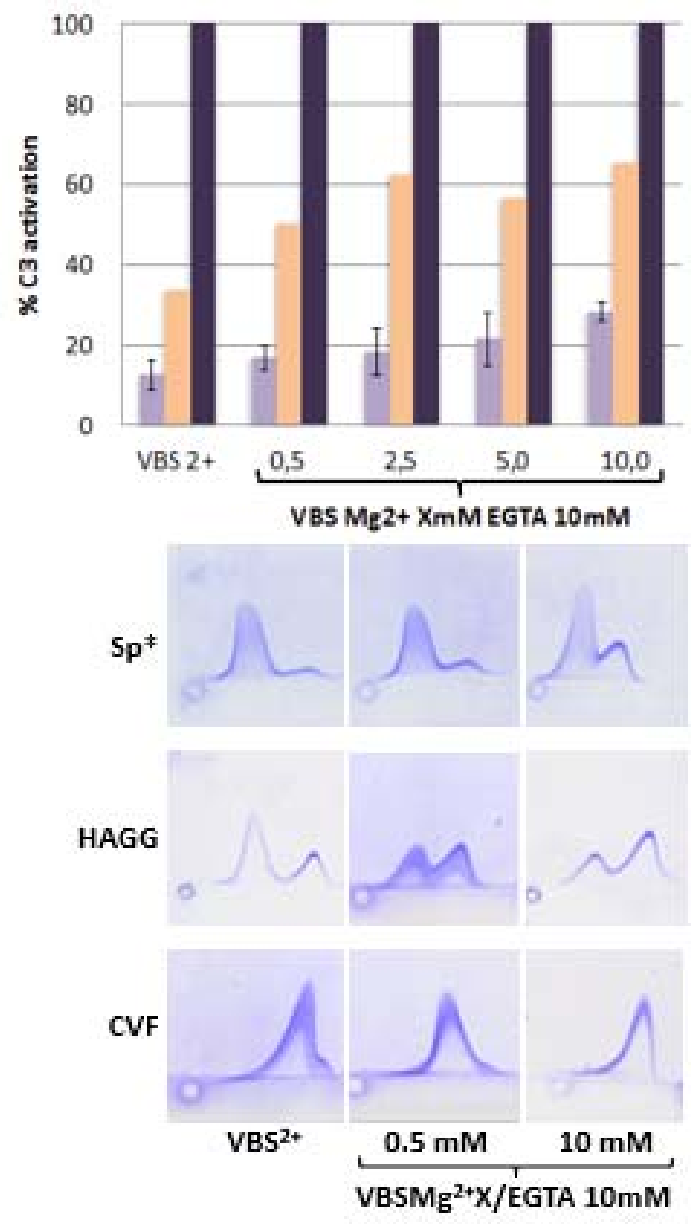

Figure 1: Protein C3 cleavage produced in controlled experiments. The upper part shows percentage of protein C3 cleavage in samples used to test spontaneous activation ( $S p^{*}$ ) (purple columns) and used as positive controls of complement activation using Heat Agglutinated Gamma Globulins (HAGG) (orange columns) and cobra venom (CVF) (Black columns). The lower part shows examples of the immunoelectrophoregrams obtained from the analysis of protein $\mathrm{C} 3$ in the different incubated serum.

Spontaneous activation produced in negative control samples incubated in $\mathrm{VBS}^{2+}$ remained low at a level generally found in the conditions in which the test was performed (Bertholon et al., 2006a, Vauthier et al., 2011). Spontaneous activation evaluated in the absence of calcium ions (tests performed in VBSMg ${ }^{2+}$ X/EGTA) also showed a low level of cleavage of the protein C3 but it tended to increase with the concentration of magnesium ions. This increase remained at a low level including at the highest concentration in magnesium $(10 \mathrm{mM})$. Assays performed with the positive control including CVF revealed a total conversion of the protein $\mathrm{C} 3$ in all conditions used to perform the test. The results were consistent with the use of this compound as a positive control of the activation cascade by calcium independent pathways (Vogel and Fritzinger, 2010). Positive control including HAGG produced a partial conversion of $\mathrm{C} 3$ in $\mathrm{VBS}^{2+}$ that was increased in $\mathrm{VBSMg}^{2+} \mathrm{X} / \mathrm{EGTA}$ to reach a plateau value around $60 \%$ conversion at $2.5 \mathrm{mM}$ magnesium. This positive control was expected to trigger the complement cascade through calcium dependent pathways. Unexpectedly, our method of monitoring of the complement system revealed that the protein C3 was even more cleaved when incubations were performed in media depleted in calcium ions. Consistently with results evaluating spontaneous activation, more C3 was cleaved in the presence of increasing concentrations in magnesium ions until it reached a plateau value at $60 \%$ conversion that was much higher than the spontaneous activation measured at corresponding concentrations in magnesium. 
Figure 2 reports the activation determined after incubation of nanoparticles $(2000 \mathrm{~cm} / \mathrm{mL})$ in serum with $\mathrm{VBS}^{2+}$. The different nanoparticles produced different level of complement activation at the tested concentration that were acknowledged by the different percentage of activated C3 found on the 2D immunoelectrophoresis gels. These results were consistent with those of previous studies (Bertholon et al., 2006a, Chauvierre et al., 2003, Coty et al., 2016, Labarre et al., 2005, Vauthier et al., 2011) (See figure $1 S$ in supporting information showing a comparison with previous measurements). Consistencies of the results over time emphasized the robustness of the preparation methods used to synthesize this series of nanoparticles that shows different capacities to trigger the activation of the complement system in a reproducible manner.

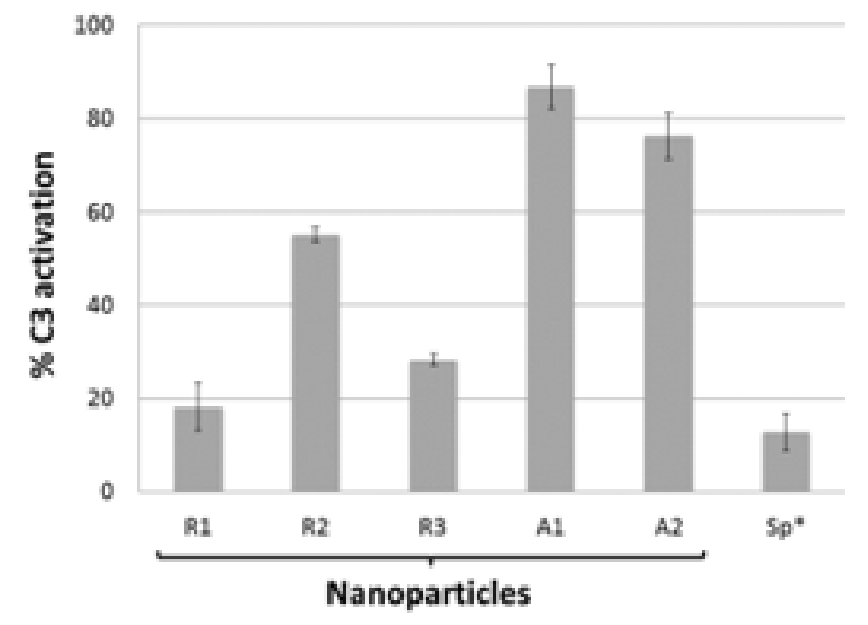

Figure 2: Percentage of protein C3 cleaved after incubation of the different nanoparticles in serum in $\mathrm{VBS}^{2+}$. Sp*: spontaneous activation found in a test performed in same experimental conditions but without nanoparticles.

Figure 3 shows results of experiments investigating complement activation produced by each type of nanoparticles in media that contained different concentrations in calcium and magnesium. These experiments were used to elucidate the preferred pathway by which the different nanoparticles triggered activation of CS. Capacity of nanoparticles to trigger complement activation through calcium dependent pathways could be highlighted by a reduction of activation between incubation in $\mathrm{VBS}^{2+}$ containing both calcium and magnesium and in $\mathrm{VBSMg}^{2+} \mathrm{X} / \mathrm{EGTA}$ that contained only magnesium.

All nanoparticles did not show full activation in $\mathrm{VBS}^{2+}$ at the concentration of $2000 \mathrm{~cm}^{2} \cdot \mathrm{mL}^{-1}$ that was the concentration tested in $\mathrm{VBS}^{2+}$ in our previous works. Thus, it was decided to also include a concentration that produced $100 \%$ of $\mathrm{C} 3$ conversion in $\mathrm{VBS}^{2+}$ in the series of tests considered in the present work. This could be achieved by increasing the concentration of the majority of the nanoparticles up to $4000 \mathrm{~cm}^{2} \cdot \mathrm{mL}^{-1}$ except for nanoparticle R1. Several situations can be described from the obtained results as summarized in table 2 . Considering tests performed at the lowest concentration in nanoparticles $\left(2000 \mathrm{~cm}^{2} \cdot \mathrm{mL}^{-1}\right)$, three different cases could be distinguished. (i) Activation was markedly reduced while calcium was removed from incubation media. This situation was observed with nanoparticles $A 1$ and $A 2$. (ii) Activation was significant and remained at the same level in all incubation media. This situation was found studying nanoparticles R2. (iii) In the third situation, the level of activation showed in $\mathrm{VBS}^{2+}$ was close to that found for the spontaneous activation. This situation was observed with nanoparticles R1 and R3 consistently with previous works and suggesting that at this concentration and in the conditions of the test these nanoparticles were inert towards the complement system (Coty et al., 2016). 


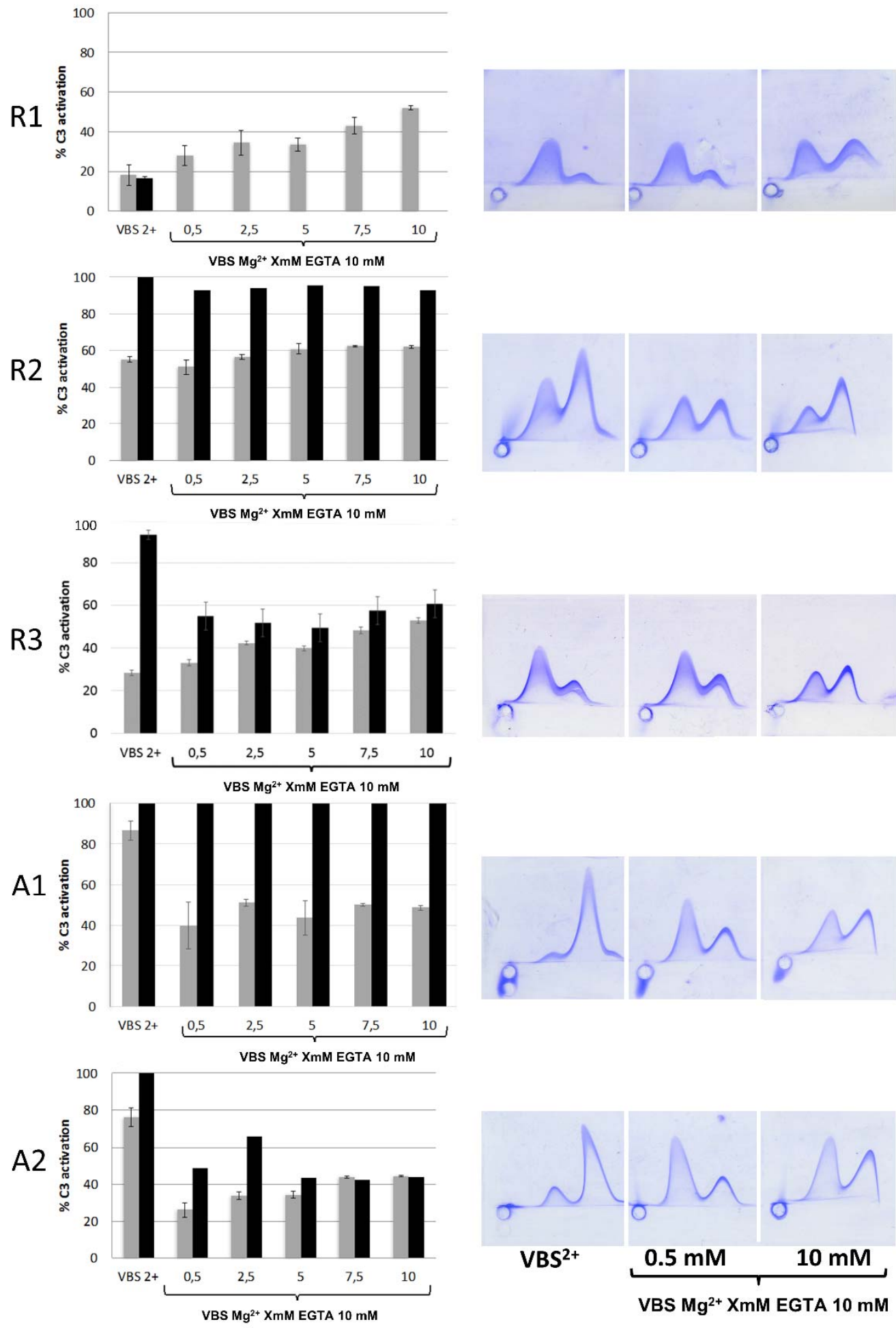

Figure 3: Activation of protein C3 produced by the different nanoparticles incubated in various conditions. Left side: percentages of cleavage of protein $\mathrm{C} 3$ produced in the different incubation media by 2 distinct concentrations in nanoparticles. Grey columns: $2000 \mathrm{~cm}^{2} / \mathrm{mL}$, dark columns: concentrations in nanoparticles required to produce $100 \%$ cleavage in $\mathrm{VBS}^{2+} .2500 \mathrm{~cm}^{2} \mathrm{~mL}^{-1}$ for nanoparticle A2, $2800 \mathrm{~cm}^{2} \mathrm{~mL}^{-1}$ for nanoparticle $R 3,4000 \mathrm{~cm}^{2} \mathrm{~mL}^{-1}$ for nanoparticles A1 and R2. Right side: examples of immunoelectrophoregrams analysis protein C3 after incubation of samples containing $2000 \mathrm{~cm}^{2} \mathrm{~mL}^{-1}$ nanoparticles in different conditions. 
Table 2: Summary of the activation of the complement cascade triggered by the different nanoparticles in the different conditions of incubations

\begin{tabular}{|c|c|c|c|c|c|}
\hline & R1 & R2 & R3 & A1 & $A 2$ \\
\hline $\begin{array}{l}\text { Model of the molecular } \\
\text { feature of the dextran } \\
\text { corona * }\end{array}$ & 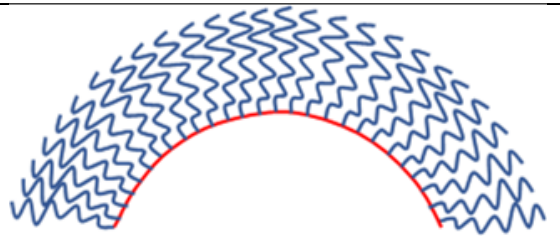 & & अ 3555 & & \\
\hline $\begin{array}{l}2000 \mathrm{~cm}^{2} / \mathrm{mL} \\
\mathrm{VBS}^{2+}\end{array}$ & $\begin{array}{l}\text { No activation (spontaneous) } \\
18 \%\end{array}$ & $\begin{array}{l}\text { Partial activation } \\
55 \%\end{array}$ & $\begin{array}{l}\text { Weak activation } \\
28 \%\end{array}$ & $\begin{array}{l}\text { Strong activation } \\
87 \%\end{array}$ & $\begin{array}{l}\text { Strong activation } \\
76 \%\end{array}$ \\
\hline $\begin{array}{l}2000 \mathrm{~cm}^{2} / \mathrm{mL} \\
\mathrm{VBSMg}^{2+} \mathrm{X} / \mathrm{EGTA}\end{array}$ & $\begin{array}{l}\text { Activation increased with }[\mathrm{Mg}] \text { up to } 52 \% \\
\text { conversion }\end{array}$ & $\begin{array}{l}\text { No effect of calcium } \\
\text { depletion } \\
\text { No effect of the increase of } \\
{[\mathrm{Mg}]}\end{array}$ & $\begin{array}{l}\text { Activation increased with }[\mathrm{Mg}] \text { up to } \\
50 \% \text { conversion }\end{array}$ & $\begin{array}{l}\text { Marked effect of calcium } \\
\text { depletion } \\
\text { No effect of the increase of } \\
{[\mathrm{Mg}]}\end{array}$ & $\begin{array}{l}\text { Marked effect of calcium } \\
\text { depletion } \\
\text { Activation increased with } \\
{[\mathrm{Mg}]}\end{array}$ \\
\hline $\begin{array}{l}\text { Maximum surface } \\
\text { VBS }^{2+}\end{array}$ & $\begin{array}{l}4000 \mathrm{~cm}^{2} / \mathrm{mL} \\
\text { No activation (spontaneous) } \\
17 \%\end{array}$ & $\begin{array}{l}4000 \mathrm{~cm}^{2} / \mathrm{mL} \\
\text { Full activation } \\
100 \%\end{array}$ & $\begin{array}{l}2800 \mathrm{~cm}^{2} / \mathrm{mL} \\
\text { Strong activation } \\
93 \%\end{array}$ & $\begin{array}{l}4000 \mathrm{~cm}^{2} / \mathrm{mL} \\
\text { Full activation } \\
100 \%\end{array}$ & $\begin{array}{l}2500 \mathrm{~cm}^{2} / \mathrm{mL} \\
\text { Full activation } \\
100 \%\end{array}$ \\
\hline $\begin{array}{l}\text { Maximum surface } \\
\text { VBSMg }{ }^{2+} \text { X/EGTA }\end{array}$ & Not determined & $\begin{array}{l}\text { Almost no effect of calcium } \\
\text { depletion } \\
\text { No effect of the increase of } \\
{[\mathrm{Mg}]}\end{array}$ & $\begin{array}{l}\text { Marked effect of calcium depletion } \\
\text { No effect of the increase of [Mg] }\end{array}$ & $\begin{array}{l}\text { No effect of calcium } \\
\text { depletion }\end{array}$ & $\begin{array}{l}\text { Marked effect of calcium } \\
\text { depletion } \\
\text { No effect of the increase of } \\
{[\mathrm{Mg}]}\end{array}$ \\
\hline Summary & $\begin{array}{l}\text { No activation in } \mathrm{VBS}^{2+} \text {, increase of the } \\
\text { activation with increasing }[\mathrm{Mg}] \text { in calcium } \\
\text { free media }\end{array}$ & $\begin{array}{l}\text { Activation by alternative } \\
\text { pathway }\end{array}$ & $\begin{array}{l}\text { Activation by classical and alternative } \\
\text { pathways } \\
\text { At a low concentration in } \\
\text { nanoparticles activation increased } \\
\text { with }[\mathrm{Mg}] \text { in calcium free media }\end{array}$ & $\begin{array}{l}\text { Low concentration in } \\
\text { nanoparticles: Activation by } \\
\text { classical and alternative } \\
\text { pathways } \\
\text { High concentration in } \\
\text { nanoparticles: activation by } \\
\text { the alternative pathway. }\end{array}$ & $\begin{array}{l}\text { Activation by classical and } \\
\text { alternative pathways. } \\
\text { At a low concentration in } \\
\text { nanoparticles activation } \\
\text { increased with }[\mathrm{Mg}] \text { in } \\
\text { calcium free media }\end{array}$ \\
\hline
\end{tabular}

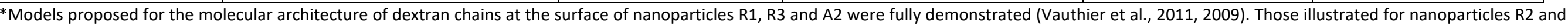

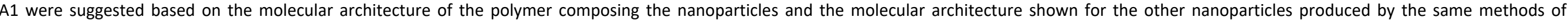
polymerization. The size scale shown by surface curvatures on the proposed models are consistent with sizes of the nanoparticles. 
However, in calcium free media containing increasing concentrations of magnesium, activation frankly increased above spontaneous activation to pass above $50 \%$ conversion of $\mathrm{C} 3$ at the highest concentration in magnesium (10 mM).

Nanoparticles tested at concentrations producing $100 \%$ activation in $\mathrm{VBS}^{2+}$ showed two types of behaviors. Nanoparticles A1 and R2 showed a full activation whatever the composition of the buffers. In contrast, a clear decrease of activation could be highlighted when evaluations were performed in calcium free media considering nanoparticles $\mathrm{A} 2$ and $\mathrm{R} 3$. No effect of the magnesium concentration was highlighted in this case. Consistent results were obtained comparing the low and high concentrations in nanoparticles considering nanoparticles A2 and R2. Conversely, at the highest concentration in nanoparticles $A 1$ no difference in the activation level was observed while a marked difference could be highlighted in tests performed with a lower concentration in nanoparticles. Again, in contrast to tests performed at the lowest concentration, nanoparticles R3 produced almost a full C3 activation (93\%) at the concentration of $2800 \mathrm{~cm}^{2}$. $\mathrm{mL}^{-1}$. Pathways of complement activation produced by these nanoparticles could be elucidated using this concentration in nanoparticles. For nanoparticles R1, it was not surprising that the activation produced remained at the level of the spontaneous activation since we have never reached the concentration threshold testing their capacity to activate the complement system at even higher concentrations than those used in the current work (Coty et al., 2016).

\section{Discussion}

The complement system is the first line host response of the innate immune system involved when the body is confronted to pathogens and any type of foreign materials circulating in the blood. Its role in detection of nanoparticles is crucial. It determines their biological functionalities, defining efficacy and safety that are linked to their immunogenic, immunosuppressive and stealth properties (Szeto and Lavik, 2016). Response of the complement system to nanoparticles can be manipulated varying characteristics of nanomaterials. For instance, size, surface composition and charge of nanomaterials influence the response of the complement system. These characteristics are generally well controlled during particle synthesis and easy to evaluate using physicochemical characterization techniques used in routine (Clogston et al., 2016, Varenne et al., 2015a, 2015b,). Activation pathways can be controlled by the molecular architecture of the polymer composing the nanoparticle corona (Hamad et al., 2010). Although it is technically possible to engineer nanoparticles with a desired structure, the lack of clear and precise guidelines to direct this design are still hampering this achievement (Szeto and Lavik, 2016). Systematic studies investigating the influence of molecular feature of nanoparticle corona on their interactions with the complement system are awaited to clarify and complete guidelines. Such studies require series of nanoparticles for which the corona structure has been resolved (Hamad et al., 2010, Hristov et al., 2015, Thomas et al., 2011). We have developed a series of polysaccharide-coated poly(isobutylcyanoacrylate) (PIBCA) nanoparticles and models of the molecular architecture of their corona were established from evidences obtained from different experimental works using different techniques (Bertholon et al. 2006b, 2006c, Chauvierre et al., 2004, Vauthier, 2015, Vauthier et al. 2011, 2009). The 5 dextran-coated nanoparticles selected for the present work showed different capacities to activate the complement system in in vitro conditions that were non-selective to discriminate 
pathways and based on the evaluation of the cleavage of the protein C3. Being all coated with dextran, these 5 nanoparticles exhibited the same surface composition and almost the same surface charges that was slightly negative. Nanoparticles $\mathrm{A} 1$ and $\mathrm{A} 2$ showed almost same hydrodynamic diameter ( $\mathrm{dH}$ $=100 \mathrm{~nm})$ and nanoparticles R1 (dH =291 $\pm 1 \mathrm{~nm}), \mathrm{R} 2(\mathrm{dH}=234 \pm 2 \mathrm{~nm})$ and R3 (dH =291 $\pm 1 \mathrm{~nm})$ were of larger diameters (Table 1). Models proposed from previous work to account for the architecture of dextran chains in the nanoparticle corona are shown in table 2 (Vauthier, 2015, Vauthier et al., 2011, 2009). General characteristics including the size and zeta potential of the nanoparticles synthesized for this work were consistent with those of previous studies as well as their capacity to activate CS evaluated in $\mathrm{VBS}^{2+}$ (see figure S1). Reproducibility obtained across different works acknowledged the robustness of the methods of synthesis of the nanoparticles and of our testing method of complement activation based on the highlight of the cleavage of protein C3 (Coty et al., 2016). This has motivated the achievement of a new work that investigated the influence of the architecture of the nanoparticle corona on their interactions with CS discriminating pathways that triggered complement activation.

Consistently with observations made by other authors investigating poly(ethyleneglycol)-coated nanoparticles, the dextran-coated nanoparticles considered here also showed a switch of complement activation pathway depending on the architecture of dextran chains in the corona (Hamad et al., 2010) (Table 2). Besides, they appealed several remarks. At first, exhibiting hydroxyl groups on their surfaces, these nanoparticles were expected to activate strongly the complement system (Szeto and Lavik, 2016, Thomas et al., 2011). Although true for nanoparticles A1, A2, R2 and R3, the nanoparticles R1 did not produced any complement activation in $\mathrm{VBS}^{2+}$ up to the highest tested concentration. Due to the presence of hydroxyl groups in the corona, it was also expected that the nanoparticles would trigger complement activation by the alternative pathway, i.e. a calcium independent mechanism, according to a mechanism that induces the cleavage of the unstable strained thioester bond of protein $\mathrm{C} 3$ when it meets nucleophiles (Thomas et al., 2011). A work by Banda et al. highlighted that dextran-coated superparamagnetic iron oxide nanoworms triggered complement activation by both the alternative and lectin pathways (Banda et al., 2014). Nanoparticles R2 appeared very selective as they triggered complement activation only through the alternative pathway. The nanoparticles $A 1, A 2$ and $R 3$ were far less selective as they triggered complement activation by both calcium dependent and independent pathways. Consistently with the work of Banda et al. it can be suggested that they triggered complement activation through the lectin and alternative pathways respectively (Banda et al., 2014). Factors such as the composition and charge of the nanoparticle surface could not be incriminated to explain the differences that were highlighted because they were mostly identical between nanoparticles. All nanoparticles were not of the same size and this factor has been identified to influence the way nanoparticles interact with the innate immune system including CS (Alexis et al., 2008, Clogston et al., 2016, Lorenzo-Abalde et al., 2016). Here the largest nanoparticles R1 $\left(d_{H}=291 \pm\right.$ $1 \mathrm{~nm}$ ) escaped complement activation although it was expected from the literature that such a property was reserved to nanoparticles having a much smaller size, preferentially bellow $200 \mathrm{~nm}$ (Alexis et al., 2008, Lorenzo-Abalde et al., 2016). For the other nanoparticles, the factor size finally reveals not being a critical factor towards complement activation. Indeed, we could observe a similar behavior of activation between R3 (291 nm) and A2 (113 nm).

Thus, it became relevant to us that the architecture of dextran chains in nanoparticles' corona greatly influenced activation of CS. Differences between the nanoparticles occurs at the molecular size scale. 
They are generally not detected by routinely applied physicochemical characterization methods but can appear huge at the size scale of proteins producing dramatic effects on the functionality and safety of the nanomaterial (Clogston et al., 2016, Hamad et al., 2010, Hristov et al., 2015,). In relation with model architectures of their corona, the nanoparticles $\mathrm{R} 2$ showing a thin corona made of a dense brush of dextran promoted activation through calcium independent mechanism only (alternative pathway). The 3 other types of nanoparticles A1, A2 and R3 were having a corona that allowed a higher accessibility of their surface to protein adsorption triggered activation by both calcium dependent (classical and/or lectin pathways) and independent (alternative pathway) mechanisms (Labarre et al., 2005, Vauthier et al., 2009). Results can be explained taking into account the accessibility of the nanoparticle surface to proteins. Nanoparticles which surfaces were accessible to large proteins (nanoparticles A1, A2 and R3) that includes immunoglobulins and protein C3 triggered activation through different pathways. Activation by the classical pathway can be triggered by immunoglobulins adsorbed on the nanoparticle surface while activation through the alternative pathway can be triggered by nucleophiles exposed on dextran chains or by the adsorbed proteins (Figure 4) (Anderson et al., 2005, Chen et al., 2016, Labarre et al., 2005, Vauthier et al., 2011, 2009). Activation triggered by the lectin pathway can occur if the polysaccharide chain shows an accessible free end chain, assuming that the configuration allowing interactions with the mannose binding lectin should be similar to that of oligosaccharides found on cell/bacteria/virus surfaces. The low density of the brush formed by dextran chains at the surface of nanoparticles R3 may be able to react with the mannose binding protein hence activating CS through the lectin pathway as well (Banda et al., 2014). In contrast, it can be assumed that the accessibility to the chain ends of dextran anchored at the surface of nanoparticles $\mathrm{A} 1$ and $\mathrm{A} 2$ is greatly hindered due to the loop and train configurations. Therefore, it was believed that the activation of CS due to a calcium dependent pathway triggered by these nanoparticles mainly occurred through the classical pathway. Due to the formation of a dense brush of dextran chains, coronas of nanoparticles R1 and R2 hamper adsorption of large proteins but small proteins can manage to adsorb on the nanoparticle core surface (Vauthier et al., 2011). The brush of nanoparticles R2 was formed with dextran of a low molecular weight. The brush thickness could be thin enough to let adsorbed proteins to protrude out of the brush. Nucleophiles from these proteins could react with the thioester bond of $\mathrm{C} 3$ protein explaining the selectively of the activation of the complement cascade through the alternative pathway (Figure 4). In the case of nanoparticle R1, results from previous work informed that the C3 protein cannot penetrate in the brush formed by dextran chains. Hence, C3 cannot be exposed to the hydroxyl groups of dextran that may trigger its activation through the alternative pathway or to glucose units that may be recognized by the lectin pathway. Due to the brush thickness formed by dextran of a high molecular weight $(49 \mathrm{~nm}$ as evaluated in a previous work (Vauthier et al., 2011), it was assumed that proteins of small size adsorbed on the nanoparticle core surface were totally engulfed in the brush being not accessible to react with the protein C3 (Vauthier et al., 2011). Also the glucose units of the dextran chains were not accessible to trigger complement activation by the lectin pathway explaining their low capacity to activate the complement system. Regulation of the activation caused by the different types of dextran coronas' architectures depends on the accessibility of the protein $\mathrm{C} 3$ to hydroxyl groups of dextran chains and on the capacity of the corona to allow proteins adsorption on the nanoparticle surface. Results suggest that accessibility of protein C3 to nucleophiles determined activation triggered by the alternative pathway (calcium independent route). It is assumed that nanoparticles can trigger the classical pathway (calcium 
dependent route) when large proteins such as immunoglobulins can adsorb on their surface and by the lectin pathway in the case glucose units that may be recognized by the mannose binding lectin protein were accessible.

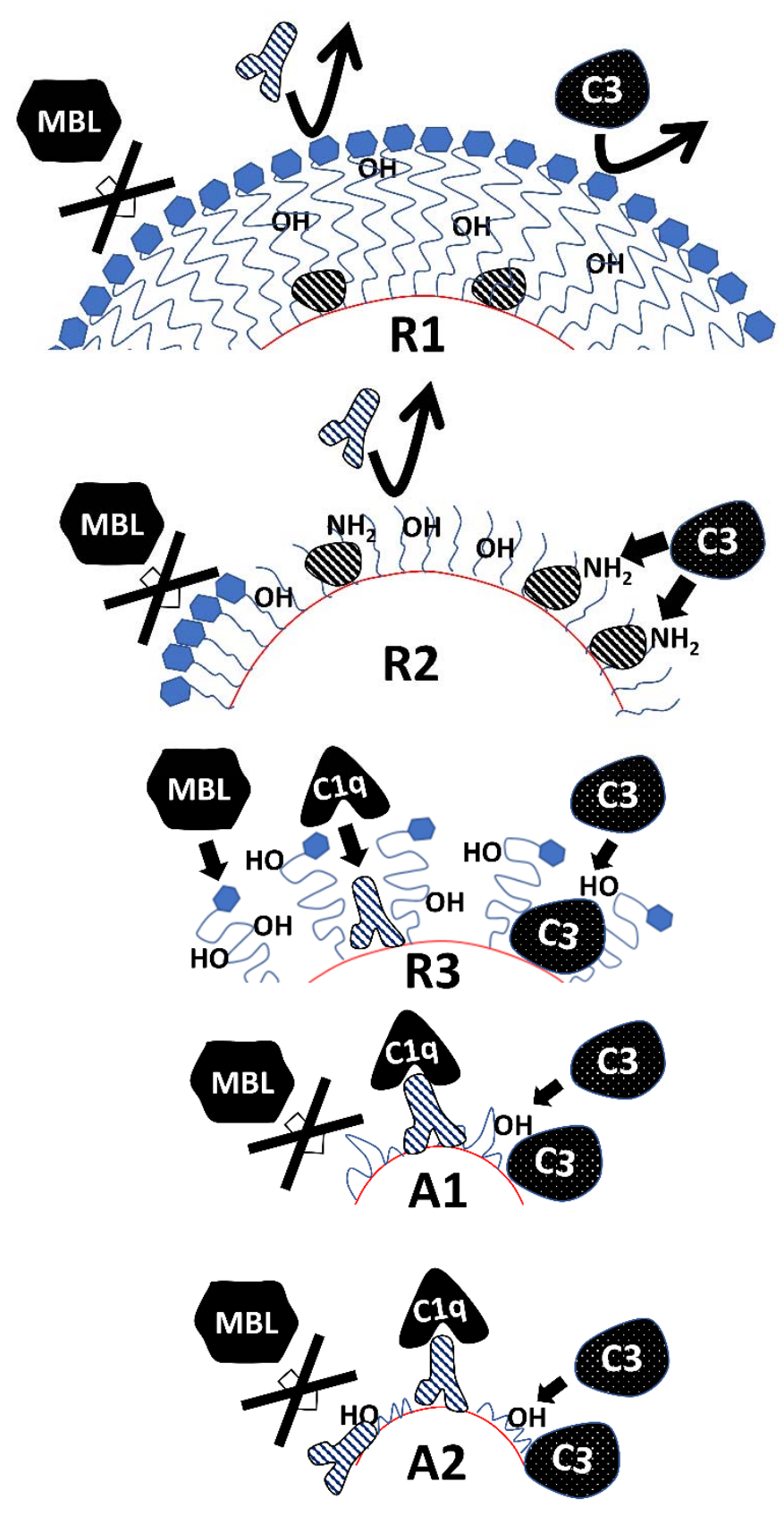

Figure 4: Assumptions on mechanisms behind interactions with proteins of the complement system that may interfere with the pathway that triggered complement activation as the function of the molecular architectures of dextran chains in the corona of the 5 types of PIBCA nanoparticle. Architecture found on nanoparticle R1 surface hampers activation of the complement system because it can hinder adsorption of large proteins and interactions with more specific proteins of the comple system (mannose bindin lectin (MBL) (MBL) and protein C3 (C3)). Architecture shown by nanoparticles $R 2$ only let access of protein $C 3$ to nucleophiles found on small proteins that can adsorb on this surface and protrude out of the brush formed by dextran chains of a low molecular weight. Architectures of the surfaces of nanoparticles R3, A1 and A2 allow large proteins to reach the nanoparticle surfaces. Immunoglobulins (a) can adsorb on these surfaces. Complement activation can be triggered through the classical pathway that involves recognition of c1a adsorbed immunoglobulins by protein $\mathrm{C} 1 \mathrm{q}$ ( Protein C3 can also adsorb on these surfaces leading to a possible direct activation through the cleavage of the unstable thioester group hidden in the protein structure. Activation of the protein $\mathrm{C} 3$ can also be triggered by nucleophilic groups of dextran chains that might be accessible for a reaction with the thioester bond considering these

architectures. Reactions that involved protein C3 straightforward trigger complement activation through the alternative pathway. Finally, activation through the mannose binding lectin pathway can also be envisaged with the architecture of dextran chains proposed for the nanoparticles $R 3$ that assumes a quite free access of the MBL to terminal glucose units of dextran chains. This pathway is probably not functioning with nanoparticles $A 1$ and $A 2$ because dextran chains of their corona form loops and trains in which access of the $M B L$ to terminal glucose units of the dextran chains might be difficult due to steric hindrance effects. 
Secondly, comparisons of the behaviors found between nanoparticles $A 1, A 2$ and nanoparticles $R 2$ point out a methodological issue. At the lower concentration in nanoparticles, they all showed a partial activation in $\mathrm{VBS}^{2+}$ and, as expected, raising the concentration in nanoparticles produced $100 \%$ activation. Results of tests performed in calcium depleted buffers $\left(\mathrm{VBSMg}^{2+} \mathrm{XmM} / \mathrm{EGTA}\right)$ were consistent at both concentrations with nanoparticles A2 and R2. At the lower concentration, nanoparticles A1 did not show preferential complement activation pathway but at the highest concentration they appeared selective as activation was triggered only through calcium independent pathways. The competition between different activation pathways highlighted at the lower concentration in nanoparticles A1 was hidden when tests were performed with a highest concentration in nanoparticles. Thus, it may be recommended to explore these mechanisms at different concentrations in nanoparticles including total and partial activations.

Finally, during these evaluations some intriguing results were observed with samples that gave low level of complement activation in $\mathrm{VBS}^{2+}$ and/or at low concentration in Magnesium in calcium free buffers $\left(\mathrm{VBSMg}^{2+} 0.5 \mathrm{mM} / \mathrm{EGTA}\right)$. An increase of activation was monitored while increasing the concentration in magnesium in the sample frankly above that of the spontaneous activation evaluated in same media. This effect, that was not yet described, concerns us. We were unable to find an explanation and further work would be necessary to explain it.

\section{Conclusion}

This work was a systematic study investigating how molecular design of nanoparticle coronas made of dextran matters on mechanisms that trigger complement activation. Dextran-coated PIBCA nanoparticles used for this work were already thoroughly characterized and known to display different capacities to triggered complement activation based on the highlight of the cleavage of protein C3. The new set of results shows that complement activation pathways can be selected by distinct architectures formed by dextran chains composing the nanoparticle corona. It also suggests assumptions that explain the relation between these mechanisms and the nanoparticle corona molecular feature. The results are of interest to rationalize the design of dextran-coated nanomaterials having defined biological perspectives that can be tuned from their interactions with the complement system. It provides with indications on how to design dextran coatings that will select complement activation pathways or prevent the nanoparticles to activate the complement system on a rational basis Although this work has resolved how molecular design of nanoparticle corona made of dextran can control mechanisms that trigger complement activation, additional works are now needed to fully understand the consequences of the activation of protein C3 produced by these nanoparticles on the full response of the innate immune system. Further work will also be needed to elucidate the occurrence of an unexplained activation of the complement system reported for the first time with low activating nanoparticles while tested in calcium free media containing increasing concentrations of magnesium.

\section{Acknowledgements}

The authors acknowledge the financial support from CNPq - PDE grant number 245564/2012-8 (Brazil) and from BPI-France, Project NICE. 


\section{Références}

Alexis, F., Pridgen, E., Molnar, L.K., Farokhzad, O.C., 2008. Factors affecting the clearance and biodistribution of polymeric nanoparticles. Mol. Pharm. 5,505-515.

Alhareth, K., Vauthier, C., Bourasset, F., Gueutin, C., Ponchel, G., Moussa, F., 2012. Conformation of surface-decorating dextran chains affects the pharmacokinetics and biodistribution of doxorubicinloaded nanoparticles. Eur. J. Pharm. Biopharm. 81, 453-457.

Andersen, A.J., Wibroe, P.P., Moghimi, S.M., 2012 Perspectives on carbon nanotube-mediated adverse immune effects. Adv. Drug Deliv. Rev. 64,1700-1705.

Anderson, J., Ekdahl, K.N., Lambris, J.D., Nilsson, B., 2005. Binding of C3 fragments on top of adsorbed plasma proteins during complement activation on a model biomaterial surface. Biomaterials. 26, 1477-1485.

Anchordoquy, T.J., Barenholz, Y., Boraschi, D., Chorny, M., Decuzzi, P., Dobrovolskaia, M.A., Farhangrazi, Z.S., Farrell, D., Gabizon, A., Ghandehari, H., Godin, B., La-Beck, N.M., Ljubimova, J., Moghimi, S.M., Pagliaro, L., Park, J.H., Peer, D., Ruoslahti, E., Serkova, N.J., Simberg, D., 2017. Mechanisms and Barriers in Cancer Nanomedicine: Addressing Challenges, Looking for Solutions. ACS Nano. 11,12-18.

Banda, N.K., Mehta, G., Chao, Y., Wang, G., Inturi, S., Fossati-Jimack, L., Botto, M., Wu, L., Moghimi, S.M., Simberg D., 2014. Mechanisms of complement activation by dextran-coated superparamagnetic iron oxide (SPIO) nanoworms in mouse versus human serum. Part. Fibre Toxicol. 11,64. doi: 10.1186/s12989-014-0064-2.

Bazile, D., Prud'homme, C., Bassoullet, M.T., Marlard, M., Spenlehauer, G., Veillard, M., 1995. Stealth Me.PEG-PLA nanoparticles avoid uptake by the mononuclear phagocytes system. J. Pharm. Sci. 84, 493-498.

Bertholon, I., Vauthier, C., Labarre D., 2006a. Complement activation by core-shell poly(isobutylcyanoacrylate)-polysaccharide nanoparticles : Influences of surface morphology, length, and type of polysaccharide. Pharm. Res. 23, 1313-1323.

Bertholon, I., Hommel H, Labarre D, Vauthier C., 2006b. Properties of polysaccharides grafted on nanoparticles investigated by EPR. Langmuir. 2006 Jun 6;22(12):5485-90.

Bertholon, I., Lesieur, S., Labarre, D., Besnard, M., Vauthier, C., 2006c. Characterization of dextranpoly(isobutylcyanoacrylate) copolymers obtained by redox radical and anionic emulsion polymerization. Macromolecules. 39, 3559-3567.

Carroll, M.V., Sim, R.B., 2011. Complement in health and disease. Adv. Drug Deliv. Rev. 63,965-975.

Chauvierre, C., Labarre, D., Couvreur, P., Vauthier, C. 2003. Novel polysaccharide-decorated poly(isobutyl cyanoacrylate) nanoparticles. Pharm. Res. 20,1786-1793.

Chauvierre, C., Vauthier, C., Labarre, D., Hommel, H., 2004. Evaluation of the surface properties of dextran-coated poly(isobutylcyanoacrylate) nanoparticles by spin-labelling coupled with electron resonance spectroscopy. Colloid Polym. Sci. 282:1016-1025.

Chen, C.C., Borden, M.A., 2011. The role of poly(ethylene glycol) brush architecture in complement activation on targeted microbubble surfaces. Biomaterials. 32, 6579-6587.

Chen, F., Wang, G., Griffin, J.I., Brenneman, B., Banda, N.K., Holers, V.M., Backos, D.S., Wu, L., Moghimi, S.M., Simberg D. (2016). Complement proteins bind to nanoparticle protein corona and undergo dynamic exchange in vivo. Nat. Nanotechnol. http://dx.doi.org/10.1038/nnano.2016.269. 
Clogston, J.D., Crist, R.M., McNeil, S.E., 2016. Physico-chemical characterization of polymer nanoparticles: challenge and present limitations. In: Vauthier, C., Ponchel, G. (Eds.), Polymer nanoparticles for nanomedicines. Springer International Publishing, Cham, Switzerland, chap 7, pp. 187-204.

Coty, J.B., Varenne, F., Vachon, J.J., Vauthier, C., 2016 Serial multiple crossed immunoelectrophoresis at a microscale: A stamp-sized 2D immunoanalysis of protein C3 activation caused by nanoparticles. Electrophoresis. 37,2401-2409.

Couvreur, P., Kante, B., Roland, M., Guiot, P., Bauduin, P., Speiser, P. 1979. Polycyanoacrylate nanocapsules as potential lysosomotropic carriers: preparation, morphological and sorptive properties. J. Pharm. Pharmacol. 31,331-332.

Couvreur, P., Vauthier, C., 2006. Nanotechnology: intelligent design to treat complex disease. Pharm. Res. 23, 1417-1450.

Crucho, C.I.C., Barros, M.T., 2015. Formulation of functionalized PLGA polymeric nanoparticles for targeted drug delivery. Polymer. 68:41-46.

D'Addio, S.M., Saad, W., Ansell, S.M., Squiers, J.J., Adamson, D.H., Herrera-Alonso, M., Wohl, A.R., Hoye, T.R., Macosko, C.W., Mayer, L.D., Vauthier, C., Prud'homme, R.K., 2012. Effects of block copolymer properties on nanocarrier protection from in vivo clearance. J. Control. Release. 162, 208-217.

Des Prez, R.M., Bryan, C.S., Hawiger, J., Colley, D.G., 1975. Function of the classical and alternate pathways of human complement in serum treated with ethylene glycol tetraacetic acid and $\mathrm{MgCl}$ ethylene glycol tetraacetic acid. Infect. Immun. 11, 1235-1243.

Dobrovolskaia, M.A., McNeil, S.E., 2013. Handbook of immunological properties of engineered nanomaterials. Vol 1.: Frontiers in nanobiomaterial research. World Scientific Publishing Co. Pte. Ltd., Singapore.

Du, X.J., Wang, J.L., Liu, W.W., Yang, J.X., Sun, C.Y., Sun, R., Li, H.J., Shen, S., Luo, Y.L., Ye, X.D., Zhu, Y.H., Yang, X.Z., Wang, J., 2015. Regulating the surface poly(ethylene glycol) density of polymeric nanoparticles and evaluating its role in drug delivery in vivo. Biomaterials. 69:1-11.

Gasque, P., 2004. Complement: a unique innate immune sensor for danger signals. Mol. Immunol. 41, 1089-1098.

Gref R., Domb, A., Quellec, P., Blunk, T., Müller, R.H., Verbavatz, J.M., Langer, R., 1995. The controlled intravenous delivery of drugs using PEG-coated sterically stabilized nanospheres. Adv. Drug Deliv. Rev. 16, 215-233.

Gref, R., Lück, M., Quellec, P., Marchand, M., Dellacherie, E., Harnisch, S., Blunk, T., Muller, R.H., 2000. 'Stealth' corona-core nanoparticles surface modified by polyethylene glycol (PEG): influences of the corona (PEG chain length and surface density) and of the core composition on phagocytic uptake and plasma protein adsorption. Colloids Surf B Biointerfaces. 18, 301-313.

Gref, R, Minamitake Y, Peracchia MT, Trubetskoy V, Torchilin V, Langer R. Biodegradable longcirculating polymeric nanospheres. Science. 1994 Mar 18;263(5153):1600-3.

Hamad, I., Al-Hanbali, O., Hunter, A.C., Rutt, K.J., Andresen, T.L., Moghimi, S.M., 2010. Distinct polymer architecture mediates switching of complement activation pathways at the nanosphere-serum interface: implications for stealth nanoparticle engineering. ACS Nano. 4, 6629-6638. 
Hamad, I., Hunter, A.C., Szebeni ,J., Moghimi, S.M., 2008. Poly(ethylene glycol)s generate complement activation products in human serum through increased alternative pathway turnover and a MASP2-dependent process. Mol. Immunol. 46, 225-232.

Harboe, M., Thorgersen, E.B., Mollnes, T.E., 2011. Advances in assay of complement function and activation. Adv. Drug Deliv. Rev. 63, 976-987.

Hristov, D.R., Rocks, L., Kelly, P.M., Thomas, S.S., Pitek, A.S., Verderio, P., Mahon, E., Dawson, K.A., 2015. Tuning of nanoparticle biological functionality through controlled surface chemistry and characterisation at the bioconjugated nanoparticle surface. Sci Rep. 5, 17040. http://dx.doi.org/10.1038/srep17040.

Ilinskaya, A.N., Dobrovolskaia, M.A., 2016a. Understanding the correlation between in vitro and in vivo immunotoxicity test for nanomedicines. J. Control. Release. 172, 456-466.

Ilinskaya, A.N., Dobrovolskaia, M.A., 2016b. Interaction between nanoparticles and plasma proteins : effects on nanoparticle biodistribution and toxicity. In: Vauthier, C., Ponchel, G. (Eds.), Polymer nanoparticles for nanomedicines. Springer International Publishing, Cham, Switzerland, chap 15, pp. 505-520.

Labarre, D., Montdargent, B., Carreno, M.P., Maillet, F., 1993. Strategy for in vitro evaluation of the Interactions between biomaterials and complement system. J. App. Biomaterials. 4, 231-240.

Labarre, D., Vauthier, C., Chauvierre, C., Petri, B., Muller, R.H., Chehimi, M.M., 2005. Interactions of blood proteins with poly (isobutylcyanoacrylate) nanoparticles decorated with a polysaccharidic brush. Biomaterials. 26, 5075-5084.

Lemarchand, C., Gref, R., Passirani, C., Garcion, E., Petri, B., Müller, R., Costantini, D., Couvreur, P., 2006. Influence of polysaccharide coating on the interactions of nanoparticles with biological systems. Biomaterials. 27, 108-118.

Li, J., Wang, Y., Liang, R., An, X., Wang, K., Shen, G., Tu, Y., Zhu, J., Tao, J., 2015. Recent advances in targeted nanoparticles drug delivery to melanoma. Nanomedicine. 11, 769-794.

Lorenzo-Abalde, S., Simon-Vazquez, R., Peleteiro Olmedo, M., Lozano-Fernandez, T., Estevez-Martinez, O., Fernandez-Carrera, A., Gonzalez-Fernandez, A., 2016. Evaluating the interactions between proteins and components of the immune system with polymer nanoparticles. In: Vauthier, C., Ponchel, G. (Eds.), Polymer nanoparticles for nanomedicines. Springer International Publishing, Cham, Switzerland, chap 9, pp. 221-290.

Merle, N.S., Church, S.E., Fremeaux-Bacchi, V., Roumenina, L.T., 2015. Complement System Part I Molecular Mechanisms of Activation and Regulation. Front. Immunol. 6, 262. http://dx.doi.org/10.3389/fimmu.2015.00262

Moghimi, S.M., Szebeni, J., 2003. Stealth liposomes and long circulating nanoparticles: critical issues in pharmacokinetics, opsonization and protein-binding properties. Prog. Lipid Res. 42, 463-478.

Moghimi, S.M., Farhangrazi, Z.S., 2013. Nanomedicine and the complement paradigm. Nanomedicine: Nanotechnol. Biol. Med. 9, 458-460.

Müller, J., Bauer, K.N., Prozeller, D., Simon, J., Mailänder, V., Wurm, F.R., Winzen, S., Landfester, K., 2017. Coating nanoparticles with tunable surfactants facilitates control over the protein corona. Biomaterials. 2017 115, 1-8.

Neun, B. W., Ilinskaya, A., Dobrovolskaia, M. A., Analysis of Complement Activation by EIA, NCL Method ITA-5.2 Version 1.2, 2015. Available from http://ncl.cancer. gov/NCL_Method_ITA-5.2.pdf (consulted on February 2017). 
Nicolas, J., Couvreur, P., 2009. Synthesis of poly(alkyl cyanoacrylate)-based colloidal nanomedicines. Wiley Interdiscip Rev Nanomed Nanobiotechnol. 1, 111-127.

Nicolas, J., Mura, S., Brambilla, D., Mackiewicz, N., Couvreur, P., 2013. Design, functionalization strategies and biomedical applications of targeted biodegradable/biocompatible polymer-based nanocarriers for drug delivery. Chem. Soc. Rev. 42, 1147-1235.

Nicolas, J., Vauthier, C., 2011. Poly(alkylcyanoacrylate) nanosystems. In: Prokop A. (Ed.). Intracellular delivery. Fundamental and applications. Springer, New York. pp. 225-250.

Őrfi, E., Szebeni, J., 2016. The immune system of the gut and potential adverse effects of oral nanocarriers on its function. Adv. Drug. Deliv. Rev. 106, 402-409.

Peracchia, M.T., Fattal, E., Desmaële, D., Besnard, M., Noël, J.P., Gomis, J.M., Appel, M., d'Angelo, J., Couvreur, P., 1999. Stealth ${ }^{\circledR}$ PEGylated polycyanoacrylate nanoparticles for intravenous administration and splenic targeting. J. Control. Release. 60, 121-128.

Peracchia, M.T., Vauthier, C., Passirani, C., Couvreur, P., Labarre, D., 1997. Complement consumption by poly(ethylene glycol) in different conformations chemically coupled to poly(isobutyl 2cyanoacrylate) nanoparticles. Life Sci. 61, 749-761.

Shi, J., Kantoff, P.W., Wooster, R., Farokhzad, O.C., 2017. Cancer nanomedicine: progress, challenges and opportunities. Nat. Rev. Cancer. 17, 20-37.

Suk, J.S., Xu, Q., Kim, N., Hanes, J., Ensign, L.M., 2016. PEGylation as a strategy for improving nanoparticle-based drug and gene delivery. Adv. Drug Deliv. Rev. 99, 28-51.

Szebeni, J., 2012. Hemocompatibility testing for nanomedicines and biologicals: predictive assays for complement mediated infusion reactions. Eur. J. Nanomed. 1, 33-53.

Szebeni, J., 2014. Complement activation-related pseudoallergy: a stress reaction in blood triggered by nanomedicines and biologicals. Mol. Immunol. 61, 163-173.

Szebeni, J., Bedőcs, P., Rozsnyay, Z., Weiszhár, Z., Urbanics, R., Rosivall, L., Cohen, R., Garbuzenko, O., Báthori, G., Tóth, M., Bünger, R., Barenholz, Y., 2012. Liposome-induced complement activation and related cardiopulmonary distress in pigs: factors promoting reactogenicity of Doxil and AmBisome. Nanomedicine. 8, 176-184.

Szebeni, J, Storm, G., 2015. Complement activation as a bioequivalence issue relevant to the development of generic liposomes and other nanoparticulate drugs. Biochem. Biophys. Res. Commun. 468, 490-497.

Szeto, G.L., Lavik, E.B., 2016. Materials design at the interface of nanoparticles and innate immunity. J. Mater. Chem. B Mater. Biol. Med. 4, 1610-1618.

Thomas, S.N., van der Vlies, A.J., O'Neil, C.P., Reddy, S.T., Yu, S.S., Giorgio, T.D., Swartz, M.A., Hubbell, J.A., 2011. Engineering complement activation on polypropylene sulfide vaccine nanoparticles. Biomaterials. 32, 2194-2203.

Toda, M., Arima, Y., Iwata, H., 2010. Complement activation on degraded polyethylene glycol-covered surface. Acta Biomaterialia. 6, 2642-2649.

Truel, L., Nienhaus, G.U., 2013. Nanoparticle interactions with plasma proteins as it relates to biodistribution. In: Dobrovolskaia, M.A., McNeil, S.E. (Eds.). Handbook of immunological properties of engineered nanomaterials. Vol 1.: Frontiers in nanobiomaterial research. World Scientific Publishing Co. Pte. Ltd., Singapore. Chap. 6, pp. 151-172. 
Varenne, F., Botton, J., Merlet, C., Beck-Broichsitter, M., Legrand F.X., Vauthier, C., 2015a. Standardization and validation of a protocol of size measurements by dynamic light scattering for monodispersed stable nanomaterial characterization. Coll and Surf A., 486:124-138.

Varenne, F., Botton, J., Merlet, C., Vachon, J.J., Geiger, S., Infante, I.C., Chehimi, M.M., Vauthier, C., 2015b. Standardization and validation of a protocol of zeta potential measurements by electrophoretic light scattering for nanomaterial characterization. Coll. and Surf. A. 486, 218-231., Erratum: Coll. and Surf A., 2016, 498, 283-284.

Vauthier, C. 2015. Interactions of polysaccharide-coated nanoparticles with proteins. In: Sutariya, V.B., Pathak, Y. (Eds.). Biointeractions of nanomaterials. CRC Press Taylor \& Francis group, Boca Raton. Chap. 18, pp. 365-382.

Vauthier, C., Labarre, D., Ponchel, G., 2007. Design aspects of poly(alkylcyanoacrylate) nanoparticles for drug delivery. J. Drug Target. 15, 641-663.

Vauthier, C., Lindner, P., Cabane, B., 2009. Configuration of bovine serum albumin adsorbed on polymer particles with grafted dextran corona. Coll. and Surf. B. 69, 207-215.

Vauthier, C., Persson, B., Lindner, P., Cabane, B., 2011. Protein adsorption and complement activation for di-block copolymer nanoparticles. Biomaterials. 32, 1646-1656.

Vauthier, C., Schmidt, C., Couvreur, P., 1999. Measurement of the Density of Polymeric Nanoparticulate Drug Carriers by Isopycnic Centrifugation. J. Nanoparticle Res. 1, 411-418.

Vittaz, M., Bazile, D., Spenlehauer, G., Verrecchia, T., Veillard, M., Puisieux, F., Labarre, D., 1996. Effect of PEO surface density on long-circulating PLA-PEO nanoparticles which are very low complement activators. Biomaterials. 17, 1575-1581.

Vogel, C.W., Fritzinger, D.C., 2010. Cobra venom factor: Structure, function, and humanization for therapeutic complement depletion. Toxicon. 56, 1198-1222.

Vonarbourg, A., Passirani, C., Saulnier, P., Benoit, J.P., 2006. Parameters influencing the stealthiness of colloidal drug delivery systems. Biomaterials. 27, 4356-4373.

Vorup-Jensen, T., Boesen, T., 2011. Protein ultrastructure and the nanoscience of complement activation. Adv. Drug Deliv. Rev. 63, 1008-1019.

Xiang, S.D., Fuschberger, M., Karlson, T.D.L., Hardy, C.L., Selonmulya, C., Plebanski, M., 2013. Nanoparticles, immunomodulation and vaccine delivery. In: Dobrovolskaia, M.A., McNeil, S.E. (Eds.). Handbook of immunological properties of engineered nanomaterials. Vol 1.: Frontiers in nanobiomaterial research. World Scientific Publishing Co. Pte. Ltd., Singapore. Chap 15, pp. 449477. 


\section{Tuning complement activation and pathway through controlled}

\section{molecular architecture of dextran chains in nanoparticle corona}

\section{Supplementary material}

\section{Jean Baptiste Coty ${ }^{\mathrm{a}}$, Elquio Eleamen Oliveira ${ }^{\mathrm{a}, \mathrm{b}}$, Christine Vauthier ${ }^{\mathrm{a}}$}

${ }^{a}$ Institut Galien Paris-Sud, CNRS, Univ. Paris-Sud, Châtenay-Malabry, France.

${ }^{\mathrm{b}}$ Centro de Ciências Biológicas e Sociais Aplicadas, Universidade Estadual da Paraíba, João Pessoa, PB 58070450, Brazil

*Corresponding Author:

Christine Vauthier

Institut Galien Paris-Sud, CNRS UMR 8612, Univ. Paris-Sud, Faculté de Pharmacie, 5 Rue J.B. Clément, 92296 Châtenay-Malabry, France.

Fax

E-mail : christine.vauthier@u-psud.fr 


\section{Supplementary material 1}

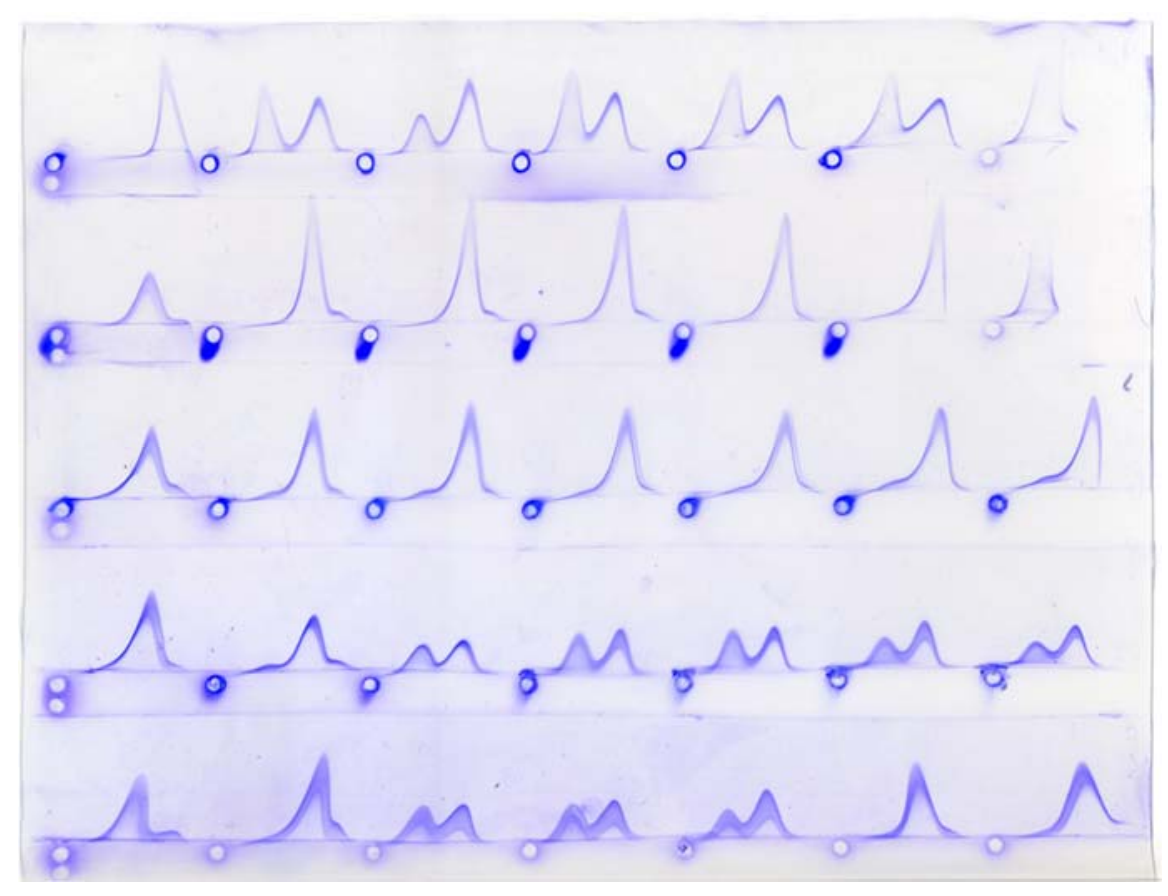

\begin{tabular}{|c|c|c|c|c|c|c|}
\hline \multicolumn{6}{|c|}{ A2 } & \multirow[b]{2}{*}{ VBS $2+\mathrm{sp}^{*}$} \\
\hline VBS $2+$ & $\begin{array}{c}\text { VBS Mg2+ } \\
0.5 \mathrm{mM}, \text { EGTA }\end{array}$ & $\begin{array}{c}\text { VBS Mg2+ } \\
2.5 \mathrm{mM}, \text { EGTA }\end{array}$ & $\begin{array}{l}\text { VBS Mg2+ } \\
\text { 5mM, EGTA }\end{array}$ & $\begin{array}{c}\text { VBS Mg2+ } \\
\text { 7.5mM, EGTA }\end{array}$ & $\begin{array}{c}\text { VBS Mg2+ } \\
\text { 10mM, EGTA }\end{array}$ & \\
\hline \multicolumn{6}{|c|}{ A1 } & \\
\hline VBS $2+$ & $\begin{array}{c}\text { VBS Mg2+ } \\
0.5 \mathrm{mM}, \mathrm{EGTA}\end{array}$ & $\begin{array}{c}\text { VBS Mg2+ } \\
2.5 \mathrm{mM}, \mathrm{EGTA}\end{array}$ & $\begin{array}{l}\text { VBS Mg2+ } \\
\text { 5mM, EGTA }\end{array}$ & $\begin{array}{l}\text { VBS Mg2+ } \\
\text { 7.5mM, EGTA }\end{array}$ & $\begin{array}{c}\text { VBS Mg2+ } \\
\text { 10mM, EGTA }\end{array}$ & VBS $2+$ sp* $^{*}$ \\
\hline \multicolumn{6}{|c|}{ R2 } & R3 \\
\hline VBS $2+$ & $\begin{array}{c}\text { VBS Mg2+ } \\
0.5 \mathrm{mM}, \text { EGTA }\end{array}$ & $\begin{array}{c}\text { VBS Mg2+ } \\
\text { 2.5mM, EGTA }\end{array}$ & $\begin{array}{l}\text { VBS Mg2+ } \\
5 \mathrm{mM}, \text { EGTA }\end{array}$ & $\begin{array}{l}\text { VBS Mg2+ } \\
\text { 7.5mM, EGTA }\end{array}$ & $\begin{array}{l}\text { VBS Mg2+ } \\
\text { 10mM, EGTA }\end{array}$ & VBS 2+ \\
\hline CVF & \multicolumn{6}{|c|}{ R3 } \\
\hline \multirow[t]{2}{*}{$\begin{array}{c}\text { VBS Mg2+ } \\
2.5 \mathrm{mM}, \text { EGTA }\end{array}$} & VBS $2+$ & $\begin{array}{c}\text { VBS Mg2+ } \\
0.5 \mathrm{mM}, \mathrm{EGTA}\end{array}$ & $\begin{array}{c}\text { VBS Mg2+ } \\
2.5 \mathrm{mM}, \text { EGTA }\end{array}$ & $\begin{array}{c}\text { VBS Mg2+ } \\
\text { 5mM, EGTA }\end{array}$ & $\begin{array}{c}\text { VBS Mg2+ } \\
7.5 \mathrm{mM}, \text { EGTA }\end{array}$ & $\begin{array}{c}\text { VBS Mg2+ } \\
\text { 10mM, EGTA }\end{array}$ \\
\hline & CVF & HAGG & HAGG & HAGG & CVF & CVF \\
\hline VBS $2+s p^{*}$ & VBS $2+$ & $\begin{array}{c}\text { VBS Mg2+ } \\
0.5 \mathrm{mM}, \text { EGTA }\end{array}$ & $\begin{array}{c}\text { VBS Mg2+ } \\
0.5 \mathrm{mM}, \text { EGTA }\end{array}$ & $\begin{array}{l}\text { VBS Mg2+ } \\
\text { 2.5mM, EGTA }\end{array}$ & $\begin{array}{c}\text { VBS Mg2+ } \\
0.5 \mathrm{mM}, \text { EGTA }\end{array}$ & $\begin{array}{c}\text { VBS Mg2+ } \\
2.5 \mathrm{mM}, \text { EGTA }\end{array}$ \\
\hline
\end{tabular}

Figure S1: Example of electrophoresis plate obtained from the Serial multiple crossed immunoelectrophoresis method applied to evaluate cleavage of protein C3 in serum incubated in different conditions with nanoparticles.

Coty JB, Varenne F, Vachon JJ, Vauthier C. Serial multiple crossed immunoelectrophoresis at a microscale: A stamp-sized 2D immunoanalysis of protein C3 activation caused by nanoparticles. Electrophoresis. 2016 Sep;37(17-18):2401-9. doi: 10.1002/elps.201500572. 


\section{Supplementary material 2}

Activation of the protein $\mathrm{C} 3$ evaluated in different works. Results that were reproduced across the different studies while performed by different lab workers suggest a high reproducibility of the methods that were used to prepare the nanoparticles and of the method applied to evaluate complement activation.

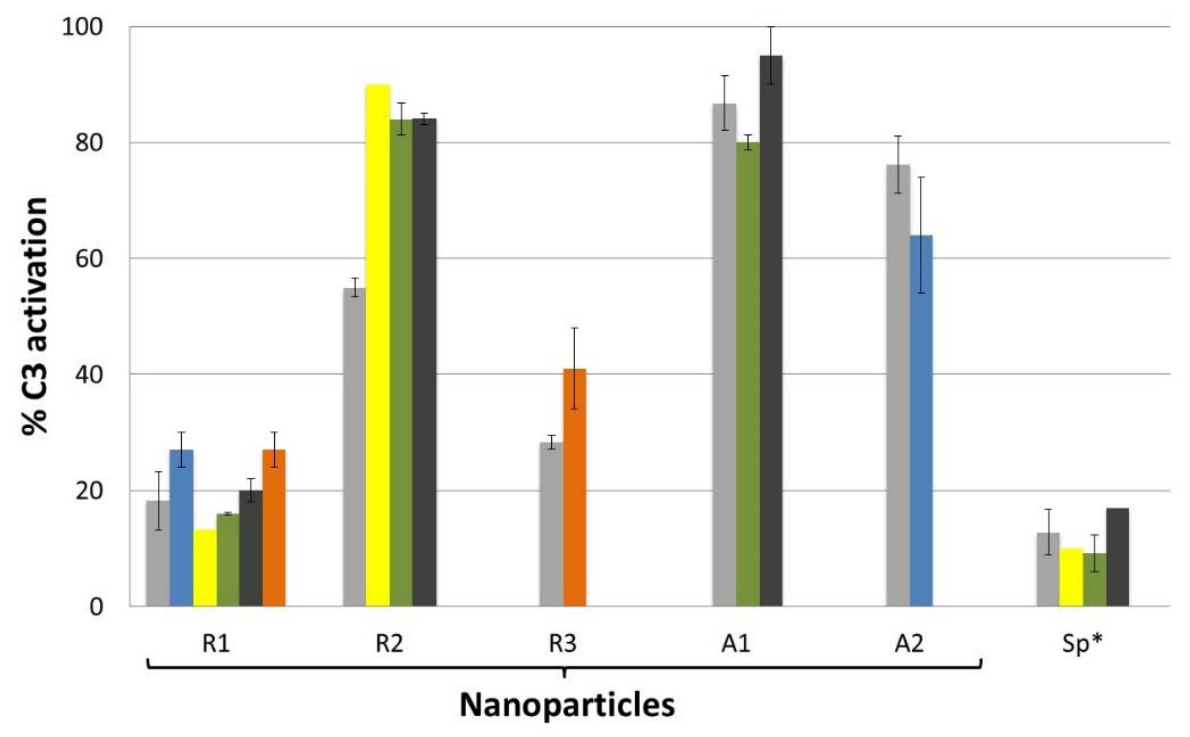

The figure 1S: Complement activation given by a series of five dextran-coated nanoparticles as evaluated from the cleavage of protein $\mathrm{C} 3$ in different works. Tests were performed by incubating the nanoparticles at a concentration of $2000 \mathrm{~cm}^{2} \cdot \mathrm{mL}^{-1}$ with serum in $\mathrm{VBS}^{2+}$. Gray [1], bleu [2], yellow [3], green [4], orange [5], black [6]

1. Current study

2. Bertholon I, Vauthier C, Labarre D. Complement activation by core-shell poly(isobutylcyanoacrylate)polysaccharide nanoparticles: Influences of surface morphology, length, and type of polysaccharide. Pharmaceutical Research. 2006;23(6):1313-23

3. Chauvierre C., Labarre D., Couvreur P., Vauthier C. Novel polysaccharide-decorated poly(isobutyl cyanoacrylate) nanoparticles. Pharmaceutical Research 20,1786-1793, 2003

4. Coty JB, Varenne F, Vachon JJ, Vauthier C. Serial multiple crossed immunoelectrophoresis at a microscale: A stamp-sized 2D immunoanalysis of protein C3 activation caused by nanoparticles. Electrophoresis. 2016 Sep;37(17-18):2401-9. doi: 10.1002/elps.201500572.

5. Vauthier C., Persson B., Lindner P., Cabane B. Protein adsorption and complement activation for diblock copolymer nanoparticles. Biomaterials, 32: 1646-1656 (2011), Available online 18 November 2010, doi:10.1016/j.biomaterials.2010.10.026

6. Labarre D., Vauthier C., Chauvierre C., Petri B., Muller R.H., Chehimi M.M. Interactions of blood proteins with poly (isobutylcyanoacrylate) nanoparticles decorated with a polysaccharidic brush Biomaterials, 26: 5075-5084 (2005) 